\title{
PERCEPÇÃO DAS MÃES COM RELAÇÃO AO PROGRAMA DO MONITORAMENTO DO DESENVOLVIMENTO AUDITIVO E DE LINGUAGEM EM LACTENTES
}

\author{
Jordani Pavan^, Maria Cecília Marconi Pinheiro Lima
}

\section{Resumo}

O objetivo deste trabalho foi identificar a percepção das mães com relação à necessidade de monitoramento do desenvolvimento auditivo e de linguagem de seus lactentes e qual o conhecimento que elas possuem sobre as consequências auditivas que os indicadores de risco podem trazer ao bebê. Estudo realizado a partir de entrevista semiestruturada com 10 questões, aplicada no momento em que o lactente estava em avaliação auditiva. Foram entrevistadas 32 mães que acompanharam seus filhos no programa de monitoramento auditivo no período de Outubro de 2018 a Abril de 2019. Observou-se que algumas mães têm ciência e são orientadas sobre o que são os indicadores de risco para a perda auditiva e o que eles podem causar no desenvolvimento do lactente. Além disso, houve uma variação de sentimentos de alívio em estar cuidando da criança e uma preocupação com o possível diagnóstico/prognóstico que possa vir a receber com o acompanhamento proposto.

\section{Palavras-chave:}

Lactente, Percepção das mães, Indicadores de Risco, Audição.

\section{Introdução}

A audição é fundamental no desenvolvimento da criança, tanto em relação à aquisição da linguagem oral, quanto à socialização e a outros comportamentos referentes à comunicação. Os primeiros anos de vida são considerados críticos para o desenvolvimento, pois é na infância que ocorre o ápice do processo de maturação do sistema auditivo central, assim como da plasticidade neuronal'2.

Lactentes com indicadores de risco para perda auditiva (IRDA) são assim considerados pela presença de condições biológicas e/ou ambientais que fazem com que aumente a incidência de atrasos ou distúrbios do desenvolvimento infantil ${ }^{1}$. O monitoramento, portanto, é uma forma de garantir que o diagnóstico não seja conclusivo apenas quando a criança já apresenta atrasos no desenvolvimento da linguagem, mas sim antes de completar seu primeiro ano de vida ${ }^{3}$.

O alto índice de evasão das famílias é considerado o principal empecilho para o sucesso dos programas de triagem auditiva. Com isso, notou-se a importância de analisar a percepção das mães em relação à necessidade do neonato ter sua audição monitorada e qual o conhecimento que possuem sobre as implicações dos indicadores de risco no desenvolvimento auditivo e de linguagem de uma criança.

\section{Método}

Trata-se de uma pesquisa transversal com análise qualitativa dos dados a partir de entrevista semiestruturada às mães que compareceram ao Programa de monitoramento do desenvolvimento auditivo e de linguagem no Centro de Estudos e Pesquisas em Reabilitação "Prof. Dr. Gabriel Porto" (CEPRE). Participaram deste estudo as mães de lactentes de ambos os sexos, nascidos no Hospital da Mulher Prof. Dr. José Aristodemo Pinotti (CAISM), em boas condições de saúde, que permaneceram em alojamento conjunto e que compareceram ao CEPRE dentro do primeiro mês de vida para a triagem auditiva e que possuem indicadores de risco para deficiência auditiva, e no momento fazem o monitoramento auditivo na mesma instituição.

\section{Resultados e Discussão}

Foi possível notar que as mães eram sucintas e diretas, com pouca riqueza de detalhes, muitas vezes respondendo "sim", "não sei", "nunca" e era notório o autoquestionamento e surpresa sobre os temas das perguntas nas suas expressões quando eram entrevistadas e nas falas apresentadas: "[...] eu nunca parei pra pensar sobre isso [...]". "Nossa! Pensando bem deve ser bem difícil, né?!".

Aproximadamente $29 \%$ das mães demonstrou não saber o motivo pelo qual seu filho foi submetido ao programa de monitoramento auditivo. Quando questionadas sobre "as principais dificuldades no desenvolvimento que uma criança deficiente auditiva pode apresentar", cerca de $33 \%$ das mães citaram a dificuldade para falar e se comunicar e $20 \%$ disseram não saber dos prejuízos, mas reconheciam como algo difícil de lidar.

\section{Conclusão}

Tais resultados demonstraram que algumas mães não tinham ciência e relataram não serem orientadas sobre o que são os indicadores de risco para a perda auditiva e o que eles podem causar no desenvolvimento do lactente. Notou-se também sentimentos de alívio por parte das mães em propiciarem esta oportunidade de investigação às crianças e preocupação com o possível diagnóstico/prognóstico que a criança possa vir a receber com o acompanhamento proposto.

${ }^{1}$ ARAÚJO DM, ROVERE NC, LIMA MCP. Development of infants with hearing impairment risk indicators and the environment classification. $J$ Hum Growth Dev. 2017.

2PENNA LM, LEMOS SMA, ALVES CRL. Habilidades linguísticas e auditivas de crianças usuárias de aparelho auditivo. Brazilian Journal of Otorhinolaryngology, São Paulo, v. 81, n. 2, mar./abr. 2015.

${ }^{3}$ LIMA MCMP, ROSSI TRF, FRANÇOSO MFC, MARBA ST, LIMA GML, SANTOS MFC. Detecção de perdas auditivas em neonatos de um hospital público. Ver Soc Bras Fonoaudiol 2010; 15(1): 01-06. 